\title{
A capacidade de resiliência de enfermeiros de instituições da área da saúde
}

\author{
Bianca Eugenia Möller ${ }^{\prime}$ \\ Cristiane Froeblich ${ }^{2}$
}

Resumo: As exigências e responsabilidades do mundo corporativo têm exigido das lideranças habilidades para lidar com pessoas e situações difíceis do cotidiano. A capacidade de o indivíduo enfrentar tais dificuldades, com positividade e aprendizado, chama-se resiliência, um comportamento que vem ganhando aplicabilidade no campo da administração e pode ser um diferencial para o exercício da liderança. $\mathrm{O}$ objetivo desta pesquisa é analisar a contribuição da resiliência para a liderança na área de enfermagem, em instituições de saúde situadas no Vale do Paranhana no Rio Grande do Sul. Realizou-se uma pesquisa de campo, descritiva e qualitativa, com dezoito respondentes. Os resultados demonstram que o ambiente no qual os enfermeiros atuam possui nível alto de estresse. Desse modo, a resiliência é indispensável para a atuação dos líderes, em face dos desafios encontrados na assistência à saúde e, também, na gestão de equipes. Tal capacidade fortalece os profissionais diante das adversidades do cotidiano.

Palavras-chave: Enfermagem. Liderança. Resiliência.

\section{The resilience of nurses in health care institutions}

\begin{abstract}
Due to the demands and responsabilities from the corporative world, the leaderships have been demanded to deal with difficult people and situations in the quotidian. The way an individual faces theses unstable situations, with positivity and learning, is called resilience. This term is known in some areas, like Physics and Psichology. However, it has been gaining applicability in the field of administration and, most of all, it can be a differential to the exercise of leadership. Based on this concept, the objective of this research is to analyse the contribution of resilience capacity to nursing leadership of health institutions located in the Paranhana Vale in Rio Grande do Sul. A descriptive, field and qualitative research was conducted with 18 respondents. The obtained results show that the ambient in which the nurses act is highly stressful, where it is possible to comprehend that the resilience is indispensable to the leaders' acting, in order to make the work routine less difficult and contribute with it. The results demonstrate that the environment in which nurses work is of high stress. Thus, the capacity for resilience is indispensable for the performance of leaders in the face of the challenges encountered in health care, and also in the management of their teams. The resilience capacity strengthens professionals in the face of daily adversities.
\end{abstract}

Keywords: Nursing. Leadership. Resilience.

\footnotetext{
1 Pós-Graduada em Comportamento e Liderança Organizacional pela Universidade Feevale. Grupo de pesquisa em Gestão do Instituto de Ciências Humanas e Sociais da Universidade Feevale. E-mail: bianca moller@yahoo.com.br. 2 Doutora em Administração pela Universidade do Vale do Rio dos Sinos (UNISINOS). Docente e Pesquisadora do Programa de Pós-Graduação Mestrado em Administração da Universidade Feevale. E-mail: cristianefroehlich@hotmail.com.
} 


\section{Introdução}

A liderança é considerada um fenômeno complexo e multidimensional, de forma que não há um consenso sobre a sua definição (BIANCHI; QUISHIDA; FORONI, 2016). Liderança pode ainda ser confundida como uma atribuição da pessoa que determina atividades aos subordinados. Por certo, liderança significa influenciar pessoas para atingir determinado objetivo (DIAS, 2003). Portanto, supõe-se que a resiliência possa auxiliar os líderes no exercício de sua profissão. É um ponto forte a ser considerado na gestão para enfrentar as adversidades de forma positiva.

A resiliência tornou-se uma capacidade necessária aos profissionais, principalmente líderes, que se deparam com situações adversas em suas rotinas. Em um mercado competitivo, é essencial que os líderes entendam cada vez mais sobre pessoas, ferramentas, estratégias e processos, para que possam extrair o melhor de suas equipes, conforme os objetivos das organizações. A resiliência constitui, portanto, a capacidade humana universal de conviver com a crise, ultrapassá-la, transformar a adversidade em aprendizado e, ainda assim, sair fortificado (ROCCA, 2011).

Diante disso, ressalta-se, nas instituições de saúde, o enfermeiro pode atuar como um gestor de assistência, pois, além de cuidar da saúde do paciente, precisa gerir uma equipe. Na condição de líder, é um recurso estratégico e multiplicador de conhecimentos que assume o papel de educador pelo fato de exercer a coordenação da equipe de enfermagem e até a gerência de unidades em geral. Por conseguinte, é visto como referência não apenas pela equipe a qual integra, mas para todos que compartilham e frequentam o mesmo ambiente (AMESTOY et al., 2010).

A capacidade de resiliência na área de saúde é essencial, pois permite aos profissionais fortalecerse diante das adversidades e participar de forma ativa e crítica diante das inúmeras situações vivenciadas no âmbito hospitalar (CHIESA, 2005; NORONHA, 2009). Desse modo, compreende-se a resiliência como um conjunto de processos sociais e intrapsíquicos que possibilita aos profissionais responder aos riscos, conforme a interação dos sujeitos com o ambiente (NORONHA, 2009).

Uma das características do trabalho na área da saúde é a constante exposição dos profissionais a situações de riscos à saúde, tanto físicos quanto psicossociais, altos níveis de estresse, fadiga e sofrimento, resultantes dos turnos prolongados de trabalhos, da falta de equipamentos e de infraestrutura hospitalar para a realização dos trabalhos (CORREIA, 2018).

Diante desse cenário, o objetivo principal desta pesquisa é analisar a contribuição da capacidade de resiliência para a prática da liderança na área de enfermagem, em instituições de saúde situadas no Vale do Paranhana no Rio Grande do Sul. Os objetivos específicos norteadores são: verificar o nível de consciência dos enfermeiros sobre resiliência; identificar a percepção desses profissionais sobre o desenvolvimento de tal capacidade no exercício da liderança; verificar as facilidades e dificuldades dos enfermeiros nesse processo.

Compõem o Vale do Paranhana as seguintes cidades: Igrejinha, Parobé, Riozinho, Rolante, Taquara e Três Coroas (GALVÃO, 1999). Cada uma possui um hospital público, exceto a cidade de 
Riozinho, que conta apenas com um posto de saúde público. Na região, Taquara é a única que possui um hospital privado.

Esta pesquisa pode contribuir para incentivar empresas e profissionais que buscam desenvolver a liderança e consideram a resiliência um ingrediente imprescindível para enfrentar situações difíceis, bem como para evitar doenças ocupacionais.

\section{Liderança e gestão na área de enfermagem}

A liderança é essencial em todos os tipos de organizações e concorre para o bom desempenho de qualquer função da administração. Davel e Machado (2001) ressaltam que os líderes são recursos estratégicos das organizações. Uma relação de liderança entre o gestor e sua equipe envolve a identidade, a cultura e as estratégias organizacionais.

Nesse sentido, conforme Bianchi, Quishida e Foroni (2016, p.54), “apesar de a liderança ser uma temática mais antiga de estudo, quando comparada à gestão estratégica de pessoas, a ênfase, apesar da evolução do campo teórico, está no indivíduo que atua como líder e não no papel exercido por este indivíduo, na organização".

Rosso et al. (2012) declaram que uma boa comunicação e visão estratégica são elementos vitais para o desenvolvimento do líder na condição de gestor e contribuem para a melhoria contínua dos processos em uma organização. Os autores descrevem a liderança em cinco atos: Ato I - Comunicação: arte de dar e receber feedback; Ato II - Gestão de pessoas: conflitos e competências; Ato III - Gestão de processos: procedimentos e produtividade; Ato IV - Gestão estratégica: visão sistêmica, visão de futuro e ferramentas estratégicas; Ato V - Gestão de equipes: a experiência e as crenças de gestão" (ROSSO et al., 2012).

Teorias sobre liderança na área de saúde explicam a realidade do enfermeiro líder. Acredita-se que esses profissionais necessitam de formação continuada em gestão de pessoas pois, "considerando que continuarão a ocorrer mudanças rápidas e significativas na enfermagem e na indústria dos cuidados da saúde, é ainda mais importante que os enfermeiros desenvolvam habilidades nos papeis de liderança e nas funções administrativas" (MARQUIS; HUSTON, 2005, p.41).

Para uma assistência efetiva, a gestão em enfermagem abrange um conjunto de tarefas, tais como: gerenciamento de recursos físicos, materiais, financeiros, políticos, de informações, gestão de pessoas (MARQUIS; HUSTON, 2005). Bortolin (2009) destaca as principais atividades dos enfermeiros direcionadas aos pacientes: cuidar, educar e gerenciar. Além dessas, consideradas assistenciais, os enfermeiros-líderes também desenvolvem ações administrativas nas organizações (LOURENÇO; TREVIZAN, 2001).

Outro ponto importante, os enfermeiros atuam em um ambiente em que os relacionamentos tendem a ser complexos e se posicionam no centro dessas relações, nas quais figuram: equipes, profissionais das demais áreas da instituição, pacientes e respectivos familiares. 
Desse modo, ao representar o ponto central das relações no ambiente hospitalar, esses profissionais assumem um papel essencial no andamento das atividades. Nessa mesma linha, Bortolin (2009) complementa, líderes que fazem a diferença e que buscam maior integração no ambiente de trabalho, aqueles que acreditam e apostam em suas equipes e olham para as mudanças e adversidades como uma oportunidade, transformam essas questões em aprendizado e impactam a vida pessoal e profissional das pessoas.

Além das atividades de rotina, os enfermeiros na posição de liderança devem adotar uma postura alinhada aos objetivos estratégicos organizacionais. Sobre isso Edersheim (2007) ressalta que, com a colaboração da equipe, cabe ao líder uma das principais atribuições do gestor: o processo de tomada de decisão. Trata-se, portanto, de uma tarefa que requer tempo e disposição mental para refletir sobre as possíveis soluções para os problemas do cotidiano. No entendimento de Lima (2013), nesse cenário, é notória a responsabilidade dos enfermeiros pela gestão dos serviços e cuidados com a saúde.

Se as organizações demandam líderes comprometidos, com a área de saúde não é diferente. Os enfermeiros assumem, portanto, um papel imprescindível na condição de gestores.

\section{Resiliência}

A palavra resiliência deriva do verbo latino resilire, que significa saltar para trás ou retornar ao estado natural. Com origem na Física, foi empregada posteriormente, em 1807, na área de Engenharia, por Thomas Young, pioneiro na análise do stress gerado pela tensão (YUNES; SZYMANSKI, 2001).

Sabbag (2012) diz que resiliência deriva do latim resilientia, do verbo resilio, que significa recuperarse, voltar ao "normal". Na física, a resiliência é uma propriedade de corpos elásticos que se modificam com a força, absorvem energia e, sem a ação de forma, retornam à forma original utilizando a energia existente.

Barros (2006) acrescenta que a palavra resiliência abriga muitas definições, cada uma conforme a área em que se aplica. Todavia, todos os significados são relevantes e levam ao mesmo entendimento: as relações interpessoais nas organizações. A definição de resiliência está cada vez mais presente na atualidade devido aos ininterruptos processos de mudanças (CABRAL; BRUSTOLIN, 2010).

Sob essa óptica, na área de administração, a resiliência volta-se para a capacidade de assimilar mudanças, enfrentar as adversidades e aprender com os desafios das organizações (SABBAG, 2012). Resiliência é, portanto, a "capacidade humana para enfrentar, sobrepor-se e ser fortalecido ou transformado por experiências de adversidades" (GROTBERG, 2002, p. 20).

Nesse sentido, a resiliência pode ser considerada um processo interativo entre indivíduo e ambiente, e o resultado interfere na maneira pela qual o indivíduo reage perante desafios (NORONHA, 2009). Como destaca Carmello (2008, p.35), “o ser resiliente é aquele que decidiu interpretar a adversidade como uma circunstância e um aprendizado da vida. Escolheu a inteligência e a esperança em vez de vitimização e do desespero". 
A resiliência contribui com os indivíduos para prevenir, minimizar ou ultrapassar situações adversas, no entanto, é importante enfatizar, não se trata de um elemento inato, tampouco de uma competência perene na vida das pessoas. Não significa, portanto, que o indivíduo saia completamente ileso de todas as situações adversas encontradas (CARMELLO, 2008; SABBAG, 2012).

Yunes (2001) entende que a resiliência é a forma por meio da qual as pessoas enfrentam as adversidades, não quer dizer que o sujeito seja invencível ao se deparar com situações difíceis. Sabbag (2012) destaca fatores relacionados à resiliência, as características que constroem tal capacidade, conforme o Quadro 1:

\section{Quadro 1: Características relacionadas à resiliência}

a) Autoeficácia: crença na própria capacidade de organizar e executar ações solicitadas para produzir resultados desejados.

b) Autoconfiança: senso de valor atribuído a si mesmo; o oposto da vitimização.

c) Otimismo aprendido: otimismo é a maneira de encarar o mundo de forma positiva, levando em consideração as dificuldades temporárias, sem assumir para si as circunstâncias, o azar ou atos de outras pessoas. O otimismo aprendido é a capacidade de contrapor emoções positivas às negativas nos momentos difíceis.

d) Temperança: é a capacidade de dosar as emoções em situações muito estressantes. Significa manter a "serenidade" ou a "frieza" diante de pressões. Destemperança é a perda do controle emocional em tais situações provocando a impulsividade.

e) Empatia: capacidade de compreender o outro em seu quadro de referência, de se colocar no lugar do outro, mantendo uma sintonia com os seus próprios sentimentos e com os dos outros. f) Competência social: é quando se permite articular apoio de outros nas situações adversas, seja para obter ajuda, seja para não se sentir desamparado.

g) Proatividade: é a propensão a atuar diante de situações adversas. Reatividade, o oposto, é a propensão apenas de reagir às situações. Inclui iniciativa, mesmo em momentos de incerteza.

h) Flexibilidade mental: possuir maior tolerância a ambiguidades. Indivíduos de baixa resiliência insistem teimosamente em táticas mesmo quando elas já se provaram não efetivas; os flexíveis persistem, tentando novas estratégias de maneira pragmática e criativa.

i) Solução de problemas: capacidade de diagnosticar problemas, planejar soluções e ter a iniciativa de agir. Significa ter uma visão prática das situações.

k) Tenacidade: pessoa capaz de suportar pressão e estressores sem sofrer distresse; é ter resistência física e mental em momentos de alta demanda.

Fonte: Adaptado de Sabbag (2012).

É possível relacionar o tema resiliência com liderança à realidade de enfermeiros líderes, os quais convivem com situações tensas, entre a assistência aos doentes e a responsabilidade com as instituições em que trabalham. Belancieri et al. (2010) observam que colaboradores da área de enfermagem enfrentam fatores estressores que podem afetar a qualidade de vida, a saúde e, consequentemente, a performance no trabalho. Os autores complementam que a situação estressante pode ocorrer ou não, dependendo da interpretação que o indivíduo faz dessa situação e do sentido que se lhe atribui. Com isso, torna-se relevante trabalhar o tema resiliência na área da saúde.

A resiliência refere-se à capacidade de o indivíduo de ser flexível e criativo em situações difíceis, sem eliminar as adversidades, mas promovendo evolução no aprendizado e viabilizando novos caminhos. Indivíduos resilientes desenvolvem atitudes que auxiliam na superação das situações estressoras: iniciativa, 
independência, autonomia, visão sistêmica, facilidade para relacionar-se com os demais, humor, criatividade, altruísmo e integridade (CAMPOS, 2014).

Diante das exigências que o mercado impõe, somadas aos desafios que os líderes enfrentam, torna-se relevante desenvolver a resiliência para não adoecer, bem como para atender às expectativas da equipe e, consequentemente, às estratégias da organização. Cabral e Brustolin (2010) complementam, por conseguinte, que o mundo contemporâneo exige das pessoas uma difícil transformação, para que seja possível enfrentar os ritmos acelerados das mudanças.

Desse modo, pode-se afirmar que "o conhecimento sistemático da resiliência é um instrumento válido e eficaz para todos os que propõem a aperfeiçoar seu campo profissional, favorecendo o enfrentamento da situação adversa" (BELANCIERI et al., 2010).

\section{A contribuição da resiliência para o exercício da liderança}

Capacidade é a habilidade utilizada para a exploração de recursos, associada aos processos organizacionais para alcançar objetivos (AMIT; SCHOEMAKER, 1993). A capacidade diz respeito a uma série de rotinas por meio das quais os gestores se habilitam a alterar a sua base de recursos para traçar estratégias e tomar decisões (EISENHART; MARTIN, 2000).

Diante de um cenário competitivo, marcado por mudanças e incertezas, as organizações impõem aos líderes o desenvolvimento de um perfil profissional que se adapte a esse contexto. Bortolin (2009) ressalta a relevância da resiliência para os gestores que se deparam com as exigências do ambiente corporativo.

Nesse sentido, a resiliência é fundamental para lidar com os desafios da rotina de trabalho. O líder resiliente adapta-se às oscilações da dinâmica organizacional e da sociedade e é capaz de aderir às situações imprevistas como um processo natural, com foco nas oportunidades, tendo em mente a auto superação (BARROS, 2006).

Líder resiliente é, portanto, aquele que enfrenta incertezas e adversidades. A resiliência é importante para o líder superar crises, problemas, obstáculos e adversidades com equilíbrio emocional em momentos de estresse (BERG, 2014).

Carmello (2008) descreve a resiliência como um conjunto de componentes observáveis em determinados profissionais, tais como: reflexão e comportamento protagonista perante desafios; enfrentamento de problemas com clara intenção de solucioná-los; criação de alternativas e disposição para melhorias; execução das ações necessárias para obter ajuda ao perceber que não conseguirá resolver determinada questão; competência para lidar com situações de ansiedade e desespero, sem desviar-se do problema; comunicação de ideias e sentimentos para evitar insatisfação.

Para França (2006), uma das atribuições do líder é desenvolver o lado psicológico da equipe. A resiliência torna-se, portanto, um diferencial diante de situações difíceis e que interfere positivamente tanto na organização quanto na vida pessoal de seus integrantes. Destaca-se ainda que "a liderança precisa ser 
flexível, resiliente, hábil para adaptar-se rápida e permanentemente, com serenidade, à turbulência das crises" (BARROS, 2006, p. 59).

Nessa óptica, declara Carmello (2008, p. 20), “a resiliência não elimina o risco da mudança, mas encoraja líderes e colaboradores a se engajarem efetivamente na situação". Para Hoch e Rocca (2006), a resiliência é essencial para o sucesso do líder que, na condição de gestor, deve conduzir as pessoas a encarar os desafios com flexibilidade, "jogo de cintura" e equilíbrio, elementos indispensáveis às adversidades do cotidiano.

O trabalho no ambiente hospitalar apresenta características peculiares e que demandam resiliência. Uma dessas características é a natureza insalubre da atividade, condição de quem lida rotineiramente com doenças. Diante disso, o sofrimento passa a fazer parte do cotidiano de um hospital, desencadeado por um processo que afeta não apenas os pacientes, mas todos que fazem parte do contexto, ou seja, os profissionais de saúde.

De acordo com contribuições de Santos et al. (2018), o foco das equipes de enfermagem é a assistência contínua e a excelência no atendimento aos pacientes. Para isso, é necessário que tais equipes sejam norteadas por líderes responsáveis por planejar e acompanhar o as atividades de seus liderados. É nesse viés que se identifica o papel do enfermeiro líder nas instituições de saúde.

As organizações precisam preocupar-se com o desenvolvimento da resiliência entre os profissionais, visto que, pessoas que não desenvolvem essa capacidade tendem a sofrer consequências que vão desde a diminuição da produtividade até o desenvolvimento de doenças, gerando resultados negativos para as instituições de saúde (BARROS, 2006). Nesse sentido, ressaltam Hoch e Rocca (2006), se os hospitais considerarem todos os aspectos que envolvem a resiliência, é possível perceber o valor dessa capacidade entre os profissionais.

Piovan (2009) destaca princípios básicos de pessoas resilientes, como por exemplo: consciência de que as adversidades são inevitáveis; necessidade de compreender a natureza humana e encontrar seu eu superior; insistência contra as adversidades; enfrentamento de problemas com vistas a tomar as devidas decisões; compreensão das dificuldades que a vida apresenta para "sair da zona de conforto" e, com isso garantir crescimento e aprendizado.

Importante salientar que, tal como ocorre com os cargos de gestão, a liderança exige um conjunto de conhecimentos e atitudes. Pessoas resilientes sabem que nada é permanente e que é preciso compreender as mudanças do mundo. Desse modo, a resiliência permite ao profissional enfrentar as adversidades e se torna um fator de proteção do sujeito perante os riscos do trabalho. Por vezes, ser resiliente pode até estimular mudanças no contexto dos envolvidos, pois é um desafio identificar o sentido da vida em situações adversas (PIOVAN, 2009; CARVALHO, 2015).

Os profissionais da área de enfermagem são mais suscetíveis aos impactos no ambiente de trabalho. Com isso, a resiliência se manifesta por meio de um processo de adaptação e de superação que possibilita a esses profissionais desenvolver atitudes para ultrapassar as adversidades. Sendo assim, a resiliência é um construto psicossocial que permite a construção de um ambiente saudável (SOUZA et al., 2017). 
O referencial teórico deste artigo apresenta conceitos sobre liderança e resiliência direcionados à atuação do enfermeiro líder. Mostrou, além disso, a contribuição da resiliência para o exercício da liderança, de forma que seja possível analisar os pontos positivos, bem como a importância dessa capacidade na área de enfermagem.

\section{Metodologia}

A metodologia científica institui regras para conferir um grau de credibilidade ao conhecimento. Uma dessas regras é a comprovação das informações apresentadas. Dessa forma, o trabalho científico não se baseia apenas em suposições, mas em dados fundamentados na realidade (PRODANOV; FREITAS, 2013).

Esta pesquisa classifica-se, quanto aos objetivos, em descritiva, seu objetivo é, portanto, descrever o contexto analisado. Quanto aos procedimentos, recorreu-se à pesquisa de campo, utilizada quando se tem uma questão a ser respondida, ou conhecimento sobre determinado problema, a ser investigado por meio da coleta de dados (PRODANOV; FREITAS, 2013). A abordagem empregada define-se como qualitativa. De acordo com Creswell e Plano (2013), dados qualitativos baseiam-se em informações extraídas de questões para as quais, na coleta de dados, não se utilizam escalas predeterminadas, ou seja, não há restrições para as respostas.

Os sujeitos da pesquisa são enfermeiros que atuam em instituições de saúde dos setores público e privado, situadas no Vale do Paranhana, no Rio Grande do Sul. Considera-se que esses profissionais atuam em ambientes com maior chance de estresse, tanto no que diz respeito ao atendimento aos pacientes quanto no âmbito organizacional. Para Müller (2004), os enfermeiros apresentam altos níveis de exaustão emocional devido às responsabilidades nos serviços de assistência à saúde, na supervisão dos profissionais da equipe de enfermagem, no cumprimento dos objetivos das instituições nas quais atuam, bem como na atividade com os médicos, no tocante ao fluxo de pacientes.

Nessa mesma linha, outros estudos retratam a realidade do trabalho do enfermeiro, que precisa empregar estratégias de enfrentamentos de situações como envolvimento emocional de pacientes e familiares, tarefas assistenciais e administrativas, sobrecarga de trabalho, falta de reconhecimento, entre outros fatores que causam estresse ao profissional (BATISTA; BIANCHI, 2006; SOUZA, 2008).

As pesquisadoras entraram em contato com as instituições para que estas indicassem os líderes que poderiam responder à pesquisa. Foram indicados vinte e cinco sujeitos. $\mathrm{O}$ instrumento de coleta de dados aplicado nesta pesquisa foi o questionário, elaborado com perguntas abertas e fechadas. A estrutura pautou-se nos objetivos da pesquisa e na base teórica. Digitado no Google Docs, o questionário foi enviado por e-mail aos vinte e cinco enfermeiros. Desse total, dezoito enviaram as respostas no período determinado.

De posse das informações, passou-se à tabulação e à análise dos dados, sendo "a parte mais extensa e visa apresentar os resultados do trabalho" (PRODANOV; FREITAS, 2013, p.116). Segundo Flick (2013), o primeiro passo da análise do conteúdo qualitativo é selecionar o material para responder 
aos objetivos da pesquisa; em seguida, examinar minuciosamente o material coletado e logo após direcionar a análise para os textos escolhidos. Nessa modalidade de investigação, o pesquisador constrói uma concepção dos dados obtidos, para encontrar possíveis explicações e realizar fluxos de causa e efeito (PRODANOV; FREITAS, 2013).

A próxima seção apresenta a análise dos resultados obtidos mediante a aplicação do questionário entre enfermeiros de instituições públicas e privadas. As respostas foram codificadas da seguinte forma: R1 para respondente 1, R2 para o respondente 2, e assim sucessivamente, até o R18, que corresponde ao total de participantes.

\section{Análise e resultados}

No que se refere ao perfil dos respondentes, $79 \%$ são do sexo feminino e $21 \%$ do sexo masculino. Quanto à idade, 63\% possuem entre 30 e 49 anos e 37\% entre 29 e 39 anos. Referente à escolaridade, $79 \%$ possuem pós-graduação e $21 \%$ ensino superior. Quanto às instituições nas quais trabalham os respondentes, $74 \%$ são de natureza privada e 26\% de natureza pública. Em relação à área de atuação, todos são da enfermagem, sendo que $79 \%$ de nível estratégico/administrativo e $21 \%$ de nível assistencial. Em relação às funções, todos ocupam cargos de liderança, sendo $79 \%$ coordenadores, 16\% gerentes e $5 \%$ supervisores.

Os dados sobre o perfil demonstram que a maioria dos profissionais é do sexo feminino, todos são enfermeiros e ocupam cargo de liderança, independentemente da natureza da instituição. A maior parte dos participantes representa o setor privado. Importante salientar que $79 \%$ dos respondentes são pós-graduados.

As primeiras questões da pesquisa são mais subjetivas. Uma delas teve o intuito de analisar o conhecimento dos respondentes sobre o conceito de resiliência. O R1 destacou que a resiliência se refere à "capacidade de se adaptar a diversas situações, em especial, situações de estresse, pressão e de dificuldade, sem você perder o controle, para manter o foco e alcançar seu objetivo". O R8 declarou:

A capacidade de resiliência é o quanto o indivíduo consegue se adaptar a situações adversas e, ainda que haja necessidade de alternar formas de comunicação, enfrentamentos e modos de fazer, o mesmo seja capaz de manter a disposição e energia para a execução das atividades e afazeres. Ou seja: o indivíduo é capaz de modificar-se, sem abrir mão de sua essência.

O R13 respondeu: "entendo pela capacidade de ser maleável, ter bom entendimento e comunicação, não resistente à mudança e melhorias, participativo, proativo, buscar por inovações e prezar pelo desenvolvimento das pessoas". O R18 complementou: "mediante situações difíceis, conseguir achar soluções sem deixar de perder o controle emocional".

As respostas obtidas demonstram que os respondentes compreendem bem o conceito de resiliência. Prova disso é a relação do que estes afirmaram com o que Rocca (2011) defende: a resiliência como uma capacidade humana universal de conviver com a crise, ultrapassá-la, transformar a adversidade 
em aprendizado e sair fortificado. Para Berg (2014), a resiliência é essencial ao líder, que deve enfrentar com equilíbrio emocional, as crises, momentos de estresse, problemas, obstáculos e adversidades,.

A questão seguinte teve o propósito de saber como os respondentes avaliam o desenvolvimento da própria capacidade de resiliência. Estas foram as declarações: R1: "Hoje tenho mais experiência, vejo que procuro pensar e avaliar bem cada situação, mas com certeza tenho que desenvolver melhor a resiliência". R2: "Acho que consigo desempenhar bem determinadas funções, porém, penso que seria necessário desenvolvê-las ainda mais". R4: "Vejo ela como um processo em constante amadurecimento". R7: “Me considero uma pessoa resiliente, são várias adaptações que passo todos os dias”. R8:

Sempre tive facilidade em adaptar-me a mudanças, sejam elas de ambiente ou na forma como enfrentar problemas ou lidar com diferentes tipos de pessoas, considerando sua personalidade. Ao longo do tempo, fui assumindo cargos progressivamente mais exigentes, o que exigiu subsídios teóricos e emocionais suficientemente robustos para que fosse possível administrar as demandas dos cargos. Assim, considero ter desenvolvido boa capacidade de resiliência.

O R12 considera o próprio desenvolvimento "uma forma de crescimento profissional". $\mathrm{Na}$ opinião do R16, "é algo que devemos nos aperfeiçoar constantemente". O R18 respondeu: "em desenvolvimento". Nota-se que a maior parte dos enfermeiros se considera resiliente diante da realidade de trabalho. A resiliência é um aprendizado contínuo dos processos de adaptação e de superação de adversidades (SOUZA et al., 2017).

Ao contrapor as respostas com o referencial teórico, percebe-se que os líderes vivem em ambientes de constantes transformações, sejam elas por mudanças organizacionais, sejam por mudanças pessoais, dos próprios indivíduos. Conforme destaca Bortolin (2009), líderes que fazem a diferença e buscam maior articulação no ambiente de trabalho, aqueles que acreditam e apostam em suas equipes e enxergam oportunidades nas mudanças e adversidades, transformam essas questões em aprendizados que impactam a vida pessoal e profissional das pessoas.

A pergunta seguinte pretendeu verificar as facilidades e dificuldades vivenciadas pelos enfermeiros no tocante à resiliência. A resposta do R1 foi:

A facilidade é que quando você desenvolve tem um reforço positivo porque você percebe se manter resiliente. A dificuldade é que no momento de estresse, o gatilho para ser impulsivo é automático, então é importante fazer uma metacognição e tentar agir diferente.

Sobre essa questão, o R2 afirmou: "o dia a dia me proporciona desenvolver essa capacidade"; o R5, "experiência e estudo"; o R6, "não consigo pensar em nenhuma facilidade no momento, quanto às dificuldades, sabatizei muito até começar a aprender”; mais extensa foi a declaração do R8:

As facilidades consistem em fixar o pensamento nas possibilidades de solução. Pensamentos otimistas geralmente conduzem a resoluções mais assertivas. Além disso, dar espaço para manifestação dos colaboradores tem sido produtivo, à medida que a variedade de abordagens potencializa a adaptação às diversas situações. Por outro lado, fixar-se nas dificuldades e empecilhos para realização de uma tarefa ou solução de problema retarda sua solução. Ao mesmo tempo, as pessoas de seu entorno parecem se 
“contagiar" com o tipo de postura adotada. Por isso, busco posições positivas e empreendedoras.

Os outros respondentes destacaram: R10, "dificuldades: empatia, administrar as emoções, controlar os impulsos. Facilidades: otimismo, ter objetivos, aprimorar-se"; R14, "a gestão da emoção acredito ser o principal impedimento, muitas vezes não conseguimos gerir o que estamos sentindo nos momentos conflituosos, essencial para o sucesso"; R18, "estresse do dia a dia, falta de autoconhecimento".

Com base nas declarações, observa-se que grande parte dos respondentes acredita ser necessário desenvolver a resiliência, devido à intensa rotina de atividades a que os profissionais da saúde se submetem. De acordo com os teóricos, "considerando-se que continuarão a ocorrer mudanças rápidas e significativas na enfermagem e na indústria dos cuidados da saúde, é ainda mais importante que os enfermeiros desenvolvam habilidades nos papeis de liderança e nas funções administrativas” (MARQUIS; HUSTON, 2005, p.41).

O propósito da última questão subjetiva foi verificar se os participantes consideram a resiliência um diferencial na liderança. Estas foram as respostas: R1, "sim, pois acredito ser importante ter essa capacidade e importante também passar para sua equipe, pois a resiliência é essencial para alcançarmos nossos objetivos"; R3, "sim, é uma capacidade que exige trabalhar com situações adversas e ainda extrair pontos positivos"; R9, "com certeza, aprender a se adaptar a diversas situações faz um líder de sucesso"; R11, “sim, equipes mais resilientes são capazes de lidar melhor com as adversidades. Adoecem menos".

O R15 afirmou: "Sim. O líder não pode demonstrar se abalar perante os problemas e sempre que o problema existir ele deve achar a melhor solução, caminho para resolvê-lo”. O R17 disse: "Com certeza! Sem a capacidade de passar por dificuldades ou situações estressantes como poderia liderar uma equipe"? Em resumo, na opinião dos respondentes, a resiliência é imprescindível para a atuação dos líderes.

A primeira questão fechada pretendeu verificar, entre os pesquisados, o percentual daqueles que conseguem controlar as emoções diante de situações estressantes. Observou-se que 79\% dos enfermeiros "quase sempre conseguem controlar as emoções em situações estressoras"; os que disseram que "sempre agem com serenidade" formam 16\%; "algumas vezes" foi a resposta de 5\% dos participantes. Os resultados relacionam-se ao fator temperança que, conforme Sabbag (2012), é a capacidade de dosar as emoções em situações muito estressantes. Significa "manter a serenidade" ou "a frieza" em face das pressões.

Com o intuito de identificar a existência de empatia, foi perguntado na questão seguinte se os respondentes compreendem quando um colaborador da equipe passa por dificuldades. Os que disseram que "quase sempre compreendem a situação ao qual o integrante da equipe pode estar passando" somam $53 \%$; os que "sempre entendem as dificuldades da equipe" totalizam 47\%. Os percentuais mostram, portanto, que a maioria dos respondentes compreende a situação do outro. Sabbag (2012) salienta que a empatia é um dos componentes da resiliência e caracteriza-se pela capacidade de compreender o outro em seu quadro de referência, de se colocar no lugar do outro, de manter a sintonia com seus próprios sentimentos e com os sentimentos do outro. 
Outra questão diz respeito à tomada de decisões. Foi questionado se os enfermeiros costumam consultar outras pessoas para resolver determinadas situações. Com base nos resultados, pôde-se verificar que $53 \%$ dos enfermeiros quase sempre consultam outras pessoas antes de tomar uma decisão. Dessa forma, pode-se dizer que a opinião dos respondentes se harmoniza com o que assegura Sabbag (2012), segundo o qual, competência social é saber articular-se com o apoio do outro nas situações adversas, seja para obter ajuda, seja para não se sentir desamparado. Significa, portanto que, por um lado, em determinadas situações, o enfermeiro, na condição de líder, necessita de tomar decisões; por outro, para alinhar-se aos valores e à cultura da instituição na qual trabalha, precisa trocar conhecimentos e experiências.

Questionou-se se os profissionais insistiam em suas próprias ações mesmo que não efetivas, verificou-se que $63 \%$ dos respondentes disseram algumas vezes ser insistentes, $26 \%$ nunca, 11\% quase sempre. A maioria respondeu insistir em ações em grande parte das vezes, acredita-se que por conta da realidade ao qual o profissional encontra-se e pelo fato de ter poder de decisão, os líderes possuem atitudes, que nem sempre são assertivas.

Questionou-se também se os profissionais insistiam em suas próprias ações, mesmo que não efetivas. Aqueles que se declararam ser, algumas vezes, insistentes somam 63\%; os que afirmaram quase sempre, $26 \%$; nunca, $11 \%$ dos respondentes. Acredita-se que a maioria revelou insistir em suas próprias ações em grande parte das vezes por dois motivos: primeiro, devido à realidade do profissional da área de enfermagem; segundo, por ter poder de decisão, os líderes possuem atitudes que, nem sempre são assertivas. Ao relacionar liderança e resiliência, os teóricos asseveram que indivíduos resilientes desenvolvem atitudes que auxiliam na superação de situações estressoras: iniciativa, independência, autonomia, visão sistêmica, facilidade em relacionar-se com os demais, humor, criatividade, altruísmo e integridade (CAMPOS, 2014).

Em outra questão, foi perguntado se os respondentes têm facilidade para detectar problemas, encontrar soluções e colocá-las em prática. Do total de participantes, $79 \%$ disseram que "quase sempre pensam em alternativas para solucionar problemas"; outros, 11\%, disseram "algumas vezes"; o restante, 10\%, "sempre". No entanto, uma das facetas da resiliência, de acordo com Sabbag (2012), é a resolução de problemas, o que significa ter a capacidade de diagnosticá-los, de planejar soluções e iniciativa para agir. Com isso, observa-se uma visão prática das situações.

A última questão quis saber se, ao se deparar com uma situação difícil, os enfermeiros apresentam reações físicas até a resolução da questão. Os respondentes assinalaram que, algumas vezes, apresentam algum tipo de reação física diante dos problemas. Importante ressaltar que, de acordo com os estudos realizados, o indivíduo resiliente não pode ser confundido com aquele que enfrenta todas as situações de forma invicta. Yunes (2001) entende que a resiliência é a forma por meio da qual as pessoas enfrentam as adversidades, não significa, portanto, que o sujeito resiliente seja invencível ao se deparar com situações difíceis. 


\section{Considerações finais}

Esta pesquisa teve o objetivo geral de analisar a contribuição da resiliência para a liderança na área de enfermagem, em instituições de saúde situadas no Vale do Paranhana, no Rio Grande do Sul. Com base nos resultados, verificou-se que os profissionais com mais experiência em gestão de pessoas e que trabalham em instituições privadas possuem uma melhor compreensão sobre a resiliência.

Em instituições públicas, em alguns casos, os enfermeiros deixam de receber incentivo das instituições em razão de trabalhar em mais de um local. Outros relatam, inclusive, não dispor de tempo para investir no autodesenvolvimento. No entanto, todos os respondentes afirmaram que a resiliência proporciona ao líder equilíbrio para enfrentar problemas cotidianos, encontrar o caminho para solucionálos, e assim, evitar impactos na própria saúde.

O primeiro objetivo específico foi verificar de que maneira os enfermeiros compreendem a resiliência. Com base nos conceitos analisados e nos dados obtidos por meio do questionário aplicado, pode-se constatar que, de maneira geral, os enfermeiros fazem uma concepção ideal dessa capacidade, a qual acreditam ser essencial para exercer o papel de líder. Os respondentes apresentaram conhecimentos sobre resiliência e práticas dessa capacidade nas possibilidades enfrentadas no cotidiano. Demonstraram, ademais, possuir equilibrio diante de situações que caracterizam resiliência, base desta pesquisa.

O segundo objetivo específico visou identificar a percepção dos enfermeiros sobre o desenvolvimento da resiliência no exercício da liderança. Alguns participantes relataram que a própria realidade da rotina de trabalho exige resiliência, do contrário, não seria possível atuar como enfermeiro.

O último objetivo específico buscou verificar as facilidades e dificuldades dos enfermeiros no que diz respeito à resiliência. De maneira geral, os profissionais relataram que, sempre que possível, buscam praticar a resiliência. Alguns declararam ter maior facilidade, outros, devido à rotina, acreditam tratar-se de um processo de constante aprendizado e amadurecimento. Pode-se afirmar que os profissionais que trabalham em ambientes colaborativos são mais resilientes.

Com esta pesquisa, foi possível expandir o conhecimento sobre a realidade dos enfermeiros da região do Vale do Paranhana. Foi possível também verificar a necessidade de debater a resiliência entre ocupantes de cargos de gestão, pois essa discussão contribui positivamente para a saúde emocional do gestor e, por conseguinte, da equipe. Verificou-se, ademais, que, sem tal capacidade, não é possível exercer um trabalho de boa qualidade com a equipe da instituição na qual esses profissionais prestam serviços, devido às consequências negativas relacionadas aos fatores de riscos vivenciados em ambientes de saúde.

Uma dificuldade deste estudo foi o número limitado de sujeitos participantes. Para estudos futuros, a sugestão é realizar pesquisas direcionadas às instituições públicas, nas quais é visível uma carência maior de recursos, com implicações negativas para as condições de trabalho das equipes de enfermagem. Também se recomendam pesquisas sobre a disseminação desse tema nas organizações, para que se obtenha mais conhecimento e prática da resiliência. 


\section{Referências}

AMESTOY, S. C. et al. Liderança dialógica nas instituições hospitalares. Revista Brasileira de Enfermagem, Florianópolis/ SC, v. 63, n. 5, p. 844 - 846, 2010.

AMIT, R.; SCHOEMAKER, P. Strategic Assets and Organizational Rent. Strategic Management Journal, v. 14, n. 1, p. 33-46, 1993.

BARROS, R. S. B. Resiliência: a nova competência do líder de sucesso na gestão empresarial do terceiro milênio. Caderno de Publicações Univag, n. 4, p. 53-63, 2007.

BATISTA, K. M; BIANCHI, E.R.F. Estresse do enfermeiro em unidade de emergência. Revista LatinoAm. Enfermagem, Ribeirão Preto, v. 14, n. 4, p. 534-539, 2006.

BELANCIERI, M. F et al. A resiliência em trabalhadores da área da enfermagem. Estudos de Psicologia, v. 27, n. 2, p. 227-233, 2010.

BERG, E. Você é resiliente? Conheça as 9 atitudes das pessoas altamente resilientes. 2014. Disponível em: http://www.administradores.com.br/artigos/carreira/voce-e-resiliente-conheca-as-9-atitudes-daspessoas-altamente-resilientes/76656/. Acesso em: 24/08/2019.

BIANCHI, E. G.; QUISHIDA, A.; FORONI, P. G. Atuação do Líder na Gestão Estratégica de pessoas: Reflexões, Lacunas e Oportunidades. RAC, Rio de Janeiro, v. 21, n. 1, p. 41-61, 2017.

BORTOLIN, A. A resiliência no processo de implantação do sistema de gestão hospitalar. 2009. 162f. Dissertação (Mestrado em Gestão de Negócios) - Universidade Católica de Santos, São Paulo, 2009.

CABRAL, P.M. F.; BRUSTOLIN, P.K.S. Desenvolvimento da capacidade de resiliência: uma alternativa frente aos desafios da contemporaneidade? In: BITENCOURT, C. (Org.). Gestão contemporânea de pessoas: novas práticas, conceitos tradicionais. $2^{\mathrm{a}}$ ed. Porto Alegre: Bookman, 2010.

CAMPOS, L. Resiliência \& habilidades sociais: reflexões acerca de suas articulações e seus desdobramentos na escola e na vida. Curitiba: Appris, 2014.

CARMELLO, E. Resiliência: a transformação como ferramenta para construir empresas de valor. São Paulo: Editora Gente, 2008.

CARVALHO, T. N. Liderança: a imagem e as práticas discursivas para a construção de sentido. Centro Universitário do Maranhão, São Luís, 2015.

CERVO, A. L.; BERVIAN, A. P. Metodologia Científica. 3. ed. São Paulo: McGraw-Hill do Brasil, 1983.

CHIESA, A. M. Autonomia e resiliência: categorias para o fortalecimento da intervenção na atenção básica na perspectiva da Promoção da Saúde. 2005. 135f. Tese de Livre Docência. Escola de Enfermagem da Universidade de São Paulo, USP, 2005.

COELHO, S. A. Resiliência em profissionais de saúde. 2018. 65f. Dissertação (Mestrado em Educação para Saúde) - Escola Superior de Tecnologia da Saúde de Coimbra, Portugal, 2018.

CRESWEll, J. W; PlAnO, V. L. P. Pesquisa de Métodos Mistos. 2. ed. Porto Alegre: Penso, 2013.

DAVEL, E.; MACHADO, H.V. A dinâmica entre liderança e identificação: sobre a influência consentida nas organizações contemporâneas. Revista de Administração Contemporânea, v. 5, n. 3, 2001.

DIAS, R. Cultura organizacional. São Paulo: Editora Alínea, 2003.

\begin{tabular}{l|c|c|c|c|c|c|c|c|c|} 
Cadernos de Ciências Sociais Aplicadas & ano XVIII & vol. 18 & $n^{\circ} 31$ & págs. 9-24 & jan./jun. 2021 & UESB & Vitória da Conquista/BA & pág. 22 \\
\hline
\end{tabular}


EDERSHEIM, E. H. A essência de Peter Drucker: uma visão para o futuro. Rio de Janeiro: Elsevier, 2007.

EISENHARDT, K. M.; MARTIN, J. Y. Dynamic capabilities: what are they? Strategic Management Journal, v. 21, p. 1105-1121, 2000.

FLICK, U. Introdução à Metodologia de Pesquisa: um guia para iniciantes. Porto Alegre: Penso, 2013.

FRANÇA, A. C. L. Comportamento organizacional: conceitos e práticas. São Paulo: Saraiva, 2006.

GALVÃO, C. A. Sistemas Industriais Localizados: O Vale do Paranhana - Complexo Calçadista do Rio Grande do Sul. Brasília, 1999.

GROTBERG, E. H. Nuevas tendências em resiliência. In: MELILLO, E.N.S. (Orgs.). Resiliencia: descobrindo las propias fortalezas. Buenos Aires: Paidós, 2002.

HOCH, L.; ROCCA, S. Sofrimento, resiliência e fé: implicações para as relações de cuidade. São Leopoldo: Sinodal/ EST, 2007.

LIMA, M.P. Comprometimento e entrincheiramento com a carreira de enfermeiros: uma análise dos vínculos em instituições hospitalares públicas e privadas. 2013. 196f. Dissertação (Mestrado em Administração) - Universidade Federal de Santa Maria, Santa Maria. 2013.

LOURENÇO, M. R.; TREVIZAN, M. A. Líderes de enfermagem brasileira: sua visão sobre a temática da liderança e sua percepção a respeito da relação liderança e enfermagem. Revista latino-Americana de Enfermagem, v. 9, n. 3, p. 14-19, 2001.

MARQUIS, B. L; HUSTON, C. J. Administração e liderança em enfermagem: teoria e prática. 4.ed. Porto Alegre: Artmed, 2005.

MÜLLER, D. V. K. A Síndrome de Burnout no Trabalho de Assitência à Saúde: estudo junto aos profissionais da equipe de enfermagem hospitalar. 2004. 101f. Dissertação (Mestrado em Engenharia) Universidade Federal do Rio Grande do Sul, Porto Alegre, RS, 2004.

NORONHA, M. G. R. C. E.; CARDOSO, P. S.; MORAES, T. N. P.; CENTA, M. L. Resiliência: nova perspectiva na promoção da saúde da familia? Centro de Educação Ambiental/SMMA, v. 14, n.2, p. 497-506, 2009.

PIOVAN, R. Resiliência: como superar pressões e adversidades no trabalho. São Paulo: Reino Editorial, 2009.

PRODANOV, C. C.; FREITAS, E. C. Metodologia do trabalho científico: métodos e técnicas da pesquisa e do trabalho acadêmico. 2. ed. Novo Hamburgo/ RS: Feevale, 2013.

ROCCA, L. S. M. L. Resiliência: uma perspectiva de esperança na superação das adversidades. In: HOCH, L. C.; ROCCA, L. S. M. (Orgs). Sofrimento, resiliência e fé: implicações para as relações de cuidade. São Leopoldo: Sinodal; 2011.

ROSSO, F. et al. Liderança em $\mathbf{5}$ atos: ferramentas práticas para gestores em instituições de saúde. São Caetano do Sul, SP: Yendis Editora, 2012.

SABBAG, P. Resiliência: Competência para enfrentar situações extraordinárias na sua vida profissional. São Paulo: Elsevier, 2012.

SANTOS et al. Percepção dos colaboradores de uma equipe de enfermagem quanto ao estilo de liderança de seu superior imediato. Revista Ciências Administrativas, v. 24, n. 1, 2018. 
SOUZA, C. Estresse ocupacional do Enfermeiro: fatores estressantes do trabalho em hospital. Universidade Federal do Rio Grande do Sul, Porto Alegre, 2008.

SOUZA, J. G.; RONCHI, C. C.; FERREIRA, T. C.; BANDEIRA, N. P. Resiliência: percepção dos profissionais de enfermagem em um hospital público de urgência. Anais... XX SemeAd - Seminários em Administração, Universidade de São Paulo, 2017.

YUNES, M. A. M.; SZYMANKY, H. Resiliência: noção, conceitos afins e considerações. In: TAVARES, J. (Org.). Resiliência e educação. 2 ed. São Paulo: Cortez, 2001.

Recebido em: 09/11/2019.

Aprovado em: 19/05/2020. 